\title{
Two novel missense variants in SPTBN2 likely associated with spinocerebellar ataxia type 5
}

\author{
Xianli Bian ${ }^{1}$. Shang Wang ${ }^{1} \cdot$ Suqin Jin ${ }^{1} \cdot$ Shunliang Xu ${ }^{1} \cdot$ Hong Zhang ${ }^{1} \cdot$ Dewei Wang ${ }^{1} \cdot$ Wei Shang $^{1} \cdot$ Ping Wang $^{1}$ (D)
}

Received: 12 December 2020 / Accepted: 17 March 2021 / Published online: 2 April 2021

(C) The Author(s) 2021

\begin{abstract}
Introduction Spinocerebellar ataxias (SCAs) are a heterozygous group of neurodegenerative disorders. Spinocerebellar ataxia type 5 (SCA5) is a rare autosomal-dominant ataxia with pure cerebellum involvement. The clinical characteristics are limb and gait ataxia, trunk ataxia, sensory deficits, abnormal eye movement, dysarthria, and hyperactive tendon reflexes. Spectrin beta nonerythrocytic 2 gene (SPTBN2), coding $\beta$-III spectrin protein, was identified to be associated with SCA5. To date, more than 19 variants of $S P T B N 2$ have been reported.

Methods A family and an apparently sporadic patient with ataxia and cerebellar atrophy were recruited from Shandong Province (China). To discover the disease-causing variants, capillary electrophoresis and targeted next-generation sequencing were performed in the proband of the family and the sporadic patient. The candidate variants were verified by Sanger sequencing and analyzed by bioinformatics software.

Results In our study, we verified two novel heterozygous variants in SPTBN2 in a SCA pedigree and a sporadic patient. The proband of the pedigree and her mother presented with walking instability and progressively getting worse. The sporadic patient suffered from slurred speech, walking instability, and drinking water choking cough. MRI examination of the proband and sporadic patient both displayed moderate cerebellar atrophy. The variants identified were traditionally conserved and predicted probably damaging and disease-causing by bioinformatics analysis.

Conclusion We identified two novel heterozygous variants of SPTBN2 resulting in severe ataxia which further delineated the correlation between the genotype and phenotype of SCA5, and pathogenesis of variants in SPTBN2 should be further researched.
\end{abstract}

Keywords Spinocerebellar ataxia type $5 \cdot$ Spectrin beta nonerythrocytic $2 \cdot$ Cerebellar ataxia $\cdot$ Targeted next-generation sequencing

\section{Introduction}

Spinocerebellar ataxias (SCAs) are a heterozygous group of neurodegenerative disorders, which are characterized by cerebellar ataxia, dysarthria, and difficulty in swallowing. SCAs have high genetic and clinical heterogeneity, and there are more than 40 subtypes of SCAs so far. More than 20 loci have been confirmed to be involved in the occurrence of SCAs [1].

Xianli Bian and Shang Wang contributed equally to this work.

Ping Wang

wping0108@163.com

Wei Shang

wshang85@aliyun.com

1 Department of Neurology, The Second Hospital of Shandong University, Jinan 250033, Shandong, China
Spinocerebellar ataxia type 5 (SCA5) is a rare autosomaldominant ataxia that purely targets the cerebellum [2], and the worldwide prevalence is $<1 \%$. Onset of SCA5 usually occurs in the early $30 \mathrm{~s}$, although it ranges from infancy to 68 years [3]. The predominantly clinical manifestations of SCA5 are limb and gait ataxia (>90\%); however, some patients also have trunk ataxia, sensory deficits, abnormal eye movements, dysarthria, and hyperactive deep tendon reflexes (25-90\%) [4].

Spectrin beta nonerythrocytic 2 gene (SPTBN2), which encodes $\beta$-III spectrin, has been known as causative gene for SCA5. $\beta$-III spectrin is a 2390 -amino acid protein including two calponin-homology $(\mathrm{CH})$ domains at the N-terminal, 17 spectrin repeats, and a pleckstrin-homology $(\mathrm{PH})$ domain at the C-terminal [5]. It is highly expressed in Purkinje cells and stabilizes membrane proteins, including glutamate receptors [6]. Currently, 20 variants in $S P T B N 2$ were discovered to be associated with SCA5. 
In the present study, we described a family and an apparently sporadic patient from Shandong Province (China) with ataxia and cerebellar atrophy. Two heterozygous variants were found using targeted next-generation sequencing.

\section{Materials and methods}

\section{Research subject}

A four-generation family with autosomal-dominant SCA5 and an apparently sporadic patient were contacted in Shandong Province, China. A written informed consent was obtained from all the participants, and the study was approved by the ethics committee of the Second Hospital of Shandong University. The genomic DNA samples were obtained from peripheral blood by standard techniques. All the participants underwent clinical, laboratory, cognitive function, and magnetic resonance imaging (MRI) examinations. The laboratory and MRI examinations were performed in the Second Hospital of Shandong University. Clinical and cognitive function examinations were carried out by an experienced neurologist.

\section{DNA extraction}

The whole-genomic DNA was extracted from peripheral blood of individuals by using the Wizard genomic DNA purification kit (Promega) according to the standard manufacturer's protocol.

\section{Targeted next-generation sequencing}

Targeted next-generation sequencing was performed in the genomic DNA of the proband and sporadic patient. Target sequences which included 730 known genes for hereditary ataxia were enriched by using customized capture probes chips (Illumina, San Diego, CA). The genomic DNA sample was randomly fragmented. Extracted DNA was processed by ligation-mediated PCR (LM-PCR) amplified, purified, and enriched. Captured LM-PCR products were analyzed using the Agilent 2100 Bioanalyzer and then loaded on Hiseq2000 platform for high-throughput sequencing. Raw data was aligned with the human hg19 reference genome using BWA software (Burrows Wheeler Aligner). GATK software (Genome Analysis Toolkit) was used to analyze the SNVs (single nucleotide variants) and frame-shift variants (insertion and deletion) in the genome. Then the population database 1000 Genomes (1000 human genome dataset), Genome AD (Genome Aggregation Database dataset) 2.1.1, and ExAC (The Exome Aggregation Consortium dataset) were used to filter the analyzed SNVs and in-frame variants. Candidate variants were screened by Human Mendelian Inheritance Database
(OMIM), Human Gene Mutation Database (HGMD), and Clinvar Databases. Interpretation of the variants followed the recommended standards of the American College of Medical Genetics and Genomics [7]. Finally, Sanger sequencing with target primers was carried out to confirm the variants.

\section{Results}

\section{Clinical features}

The family pedigree demonstrates an autosomal-dominant pattern of inheritance (Fig. 1a). The proband was a 53-yearold female with ataxias for 5 years, and she suffered from walking on cotton and reacting slowly. Her ataxia symptoms have been getting worse especially in the last 1 year before she was referred to our hospital. She got married at 24 years old and had two healthy daughters. She had an obvious family history of cerebellar ataxia. Her mother was 80 years old and began with ataxia at about age 40 , dysarthria at age 75 , and drinking water choking cough at age 78 . Her elder sister and fifth younger sister showed signs of ataxia at about 50 and 44 years old, respectively (Table 1). Her mother was half-sister to her aunt and uncle. Her physical examination revealed dysarthria and cerebellar ataxia. No gaze-evoked nystagmus and pyramidal signs were observed. Her cognitive function assessment scale Mini-Mental State Examination (MMSE) score was 19 and Montreal Cognitive Assessment (MoCA) score was 7. Laboratory analysis revealed normal levels of vitamin B12, thyroid function, and rheumatism series index. Her brain MRI revealed moderate cerebellar atrophy (Fig. 2a-c). Her spine MRI and electromyography (EMG) showed no obvious abnormality.

The apparently sporadic individual was a 64-year-old male with slurred speech for 10 years and ataxia and drinking water choking cough for more than 4 years (Fig. 1b). His cerebellar ataxia symptoms have been getting worse especially in the last week. He stood unsteadily and was hard to turn around. He

Table 1 Clinical features of the SCA5 family

\begin{tabular}{llll}
\hline & Sex & Age of onset & Symptoms \\
\hline Proband (III 4) & F & 48 years & Cerebellar ataxia \\
II 1 & M & 50 years & Cerebellar ataxia, dysarthria \\
II 2 & F & 55 years & Cerebellar ataxia \\
II 3 & F & 40 years & $\begin{array}{l}\text { Cerebellar ataxia, dysarthria } \\
\text { drinking water choking cough }\end{array}$ \\
III 2 & F & 50 years & Cerebellar ataxia, dysarthria \\
III 6 & F & 44 years & Cerebellar ataxia \\
IV 1 & F & 32 years & Cerebellar ataxia \\
\hline
\end{tabular}


a

II

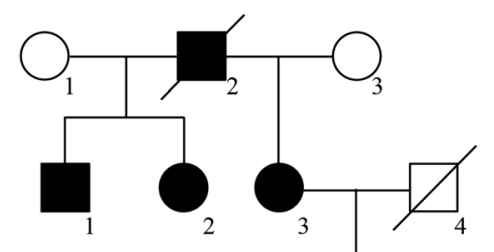

III

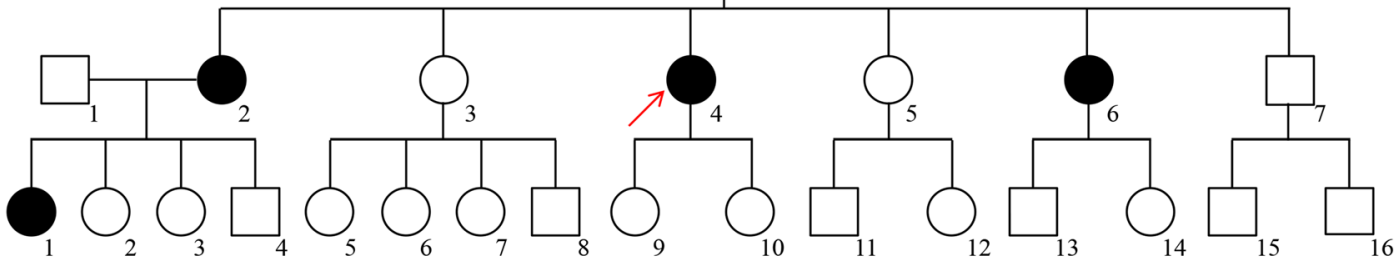

b

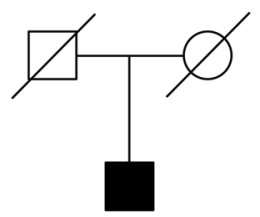

Fig. 1 Pedigree of the SCA5 family and the apparently sporadic patient. a Pedigree of a Chinese SCA5 family with autosomal-dominant inheritance. The proband and her mother presented with walking instability

and progressively getting worse. b The sporadic patient suffered fromslurred speech, walking instability, and drinking water choking cough

visited our hospital last year with partial communication disorders. He had hypertension for 10 years. It was difficult to trace back his family history because his parents passed away. He got married at 30 years old and had a healthy daughter. Physical examination revealed gaze-evoked nystagmus, cerebellar ataxia, and dysarthria. No pyramidal signs were observed. His cognitive function assessment scale MMSE score was 25 and MoCA score was 14. Laboratory analysis revealed normal levels of organic acids in the urine. Brain MRI revealed moderate cerebellar atrophy (Fig. 2d-f). a

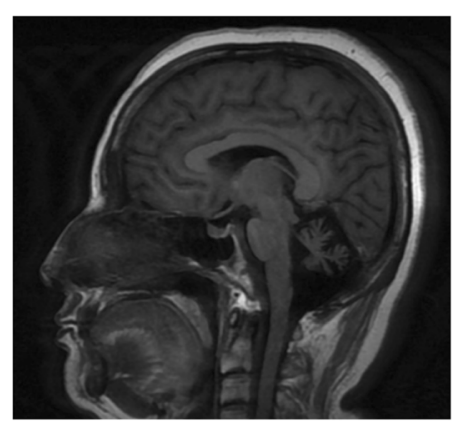

d

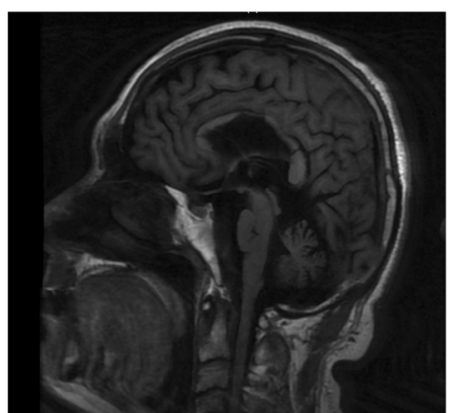

b

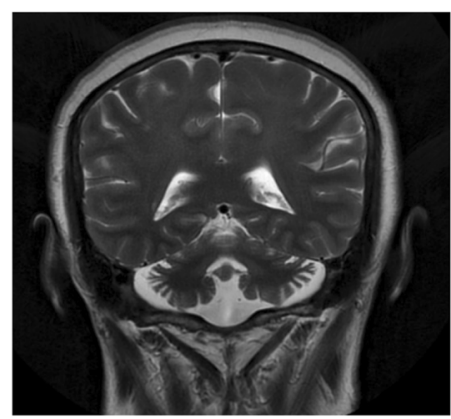

e

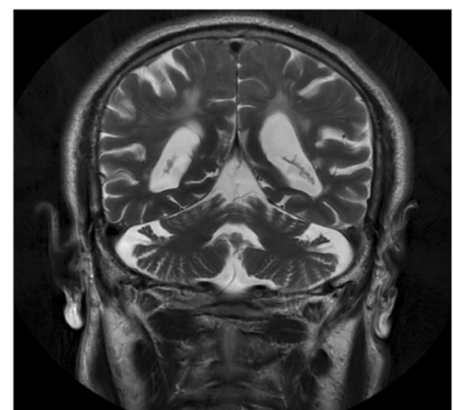

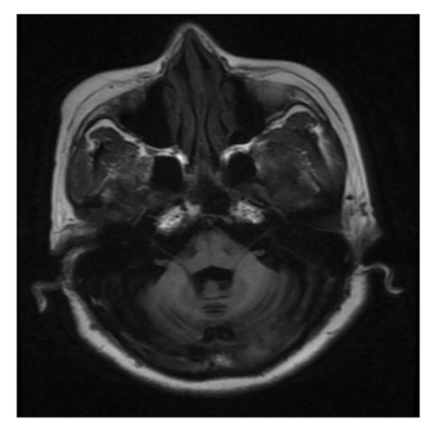

f

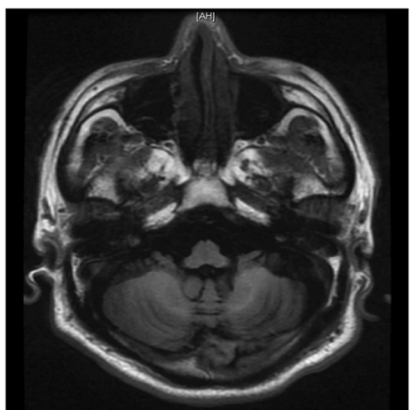

Fig. 2 Brain MRI of patients with SCA5. Sagittal (a T1-weighted), coronal (b T2-weighted), and axial (c T1-weighted) brain MRI of the proband of the family with SCA5. Sagittal (d T1-weighted), coronal (e
T2-weighted), and axial (f T1-weighted) brain MRI of the sporadic patient with SCA5. They both displayed moderate cerebellar atrophy 


\section{Mutation analysis}

We verified two novel heterozygous variants in SPTBN2 by targeted next-generation sequencing and capillary electrophoresis in the genomic DNA of the proband and the sporadic patient. Seven hundred thirty mutations and CAG repeat mutations (data not shown) associated with SCAs were analyzed. A novel missense variant (c.486C $>$ G p.I162M) of SPTBN2 was found in the proband (Fig. 3a). Sanger sequencing was subsequently performed in the genomic DNA of all family members. We found that the heterozygous variant cosegregated with phenotype of this family. Moreover, the variant was not observed in 150 unrelated healthy control and databases of normal sequence variations (1000 Genome Project and Single-Nucleotide Polymorphism Database). The identified variant was located in the $\mathrm{CH}$ domain of $\beta$-III spectrin protein (Fig. 4a). The region is highly conserved, with the Ile162 residue found in all five human $\beta$-III spectrin proteins as well as in mouse, rabbit, elephant, and chimpanzee (Fig. 4b). We conducted bioinformatic analysis using Polyphen-2 and Mutation Taster software, which predicted that the variants were probably damaging and disease-causing, respectively. Therefore, the discovered variant in SPTBN2 was likely to be pathogenic.
Targeted next-generation sequencing and capillary electrophoresis were performed to identify the causative gene of the sporadic patient. A heterozygous variant (c.2648G $>$ T p.R883L) of SPTBN2 was discovered (Fig. 3b). The highest population minor allele frequency of the variant was $<0.005$. However, the segregation analysis failed to be performed because his parents were not alive. The variant was located in the spectrin repeat domain and conserved in five species (Fig. 4a, c). The variant was predicted probably damaging and disease-causing by Polyphen-2 and Mutation Taster.

\section{Discussion}

SCA5 is a rare and pure cerebellar ataxia, which was characterized by uncoordinated gait, limb and eye movements, slurred speech, and dysarthria [5]. Onset of SCA5 is in the 3 rd or 4th decade, ranging from infancy to 68 years. In this study, we verified two novel heterozygous variants in SPTBN2, c.486C $>$ G p.I162M in a pedigree and c. $2648 \mathrm{G}>\mathrm{T}$ p.R883L in the sporadic patient, both with cerebellar ataxias, dysarthria, and cognitive dysfunction by targeted nextgeneration sequencing. The proband of the pedigree and her
Fig. 3 Sanger sequencing of SPTBN2 mutations identified in the research. a Sanger sequencing results of the missense mutation (c.486C $>\mathrm{G}$ ) in the proband (III 4) and the wide-type sequences (IV 9) in unaffected control. b Sanger sequencing results of the missense mutation (c.2648G $>\mathrm{T}$ ) in sporadic patient a

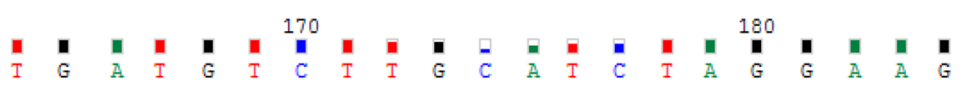

III 4

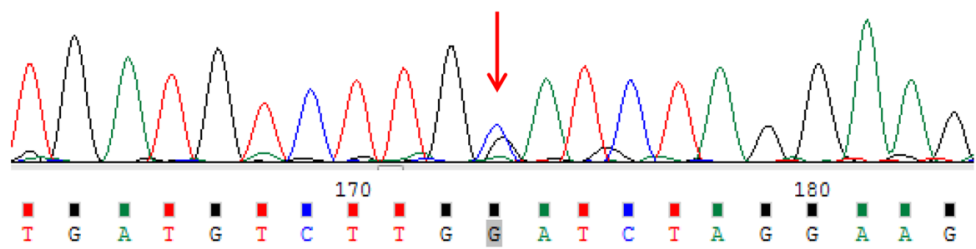

IV 9

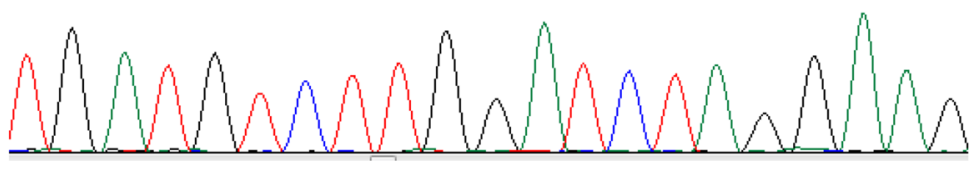

SPTBN2 c. $486 C>$ G p.I162M

b

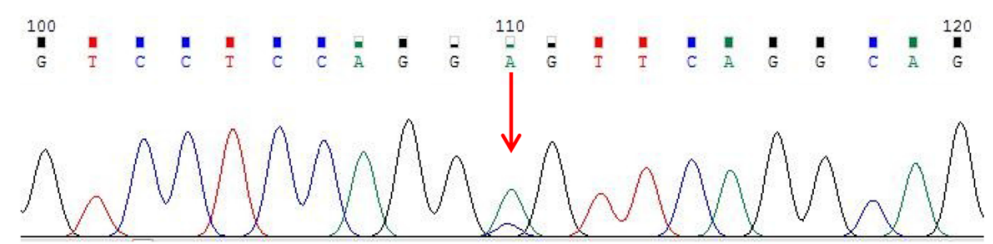

SPTBN2 c.2648G $>$ T p.R883L 
a

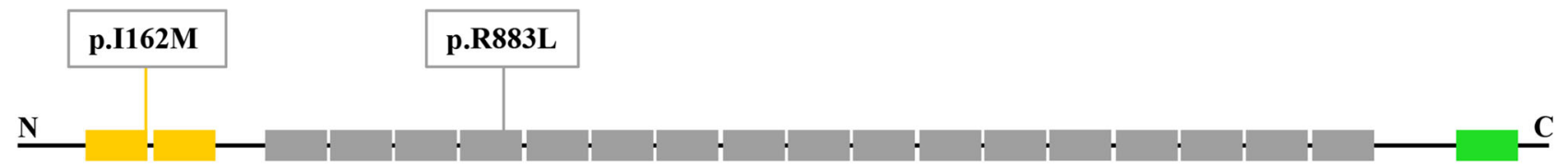

CH domain

Spectrin repeat

PH domain

b

Rabbit

Elephant

Mouse

Human

Chimpanzee

MRIHCLENVDKALQFLKEQKVHLENMGSHDIVDGNHRLTLGLVWTIILRFQIQDISVETE

MRIHCLENVDKALQFLKEQKVHLENMGSHDIVDGNHRLTLGLVWTI ILRFQIQDISVETE

170 MRIHCLENVDKALQFLKEQKVHLENMGSHDIVDGNHRLTLGLVWTIILRFQIQDISVETE MRIHCLENVDKALQFLKEQKVHLENMGSHDIVDGNHRLTLGLVWTIILRFQIQDISVETE MRIHCLENVDKALQFLKEQKVHLENMGSHDIVDGNHRLTLGLVWTIILRFQIQDISVETE

C $* * * * * * * * * * * * * * * * * * * * * * * * * * * * * * * * * * * * * * * * * * * * * * * * * * * * * * * * * * * *$

Rabbit
Elephant
Mouse
Human
Chimpanzee

EQHYQELQARAGERARALEAALALYTMLSEAGACGLWVEEKEQWLNGLALPERLEDLEVV EQHYQELQARAGERARALEAALALYTMLSEAGACGLWVEEKEQWLNGLALPERLEDLEVV EQHYEELQARAGERARALEAALAFYTMLSEAGACGLWVEEKEQWLNGLALPERLEDLEVV ERHYEELQARAGERARALEAALALYTMLSEAGACGLWVEEKEQWLNGLALPERLEDLEVV ERHYEELQARAGERARALEAALALYTMLSEAGACGLWVEEKEQWLNGLALPERLEDLEVV *: $* *: * * * * * * * * * * * * * * * * * *$ : $* * * * * * * * * * * * * * * * * * * * * * * * * * * * * * * * * * * *$

897

890

890

890

890
Fig. 4 Evolutionary conservation of the identified mutations in SPTBN2. a Mutations in this work indicated in the schematic representation of $\beta$-III

mother presented with walking instability and progressively getting worse. Her mother also developed glossolalia and drinking water choking cough. The sporadic patient suffered from slurred speech, walking instability, and drinking water choking cough. MRI examination of the proband and sporadic patient both displayed moderate cerebellar atrophy.

In 1994, Ranum and colleagues mapped the causative gene of SCA5 to the centromeric region of chromosome 11 in a single family descending from the grandparents of President Abraham Lincoln [3]. The SCA5 family had earlier ages of onset in progressive generations. Juvenile onset patients present with evidence of cerebellar and pyramidal trace dysfunction. The second SCA5 family originating from France was described with a slowed progressive cerebellar syndrome. In addition, brisk reflexes, nystagmus, facial myokymia, and decreased vibration sense were displayed in partial patients [8]. Burk et al. reported the third family with autosomal-dominant cerebellar ataxia tightly linked to SCA5 locus from Germany [9]. The patients showed a purely cerebellar syndrome with a downbeat nystagmus occurring prior to the development of other features. Ikeda et al. have discovered that an in-frame variant (c.1592_1630del39; p.E532_M544del) in SPTBN2 was pathogenic for the 11-generation American kindred [5].

To date, 20 variants of SPTBN2 have been reported for SCA5: 16 missense variants (p.L626P, p.R480W [10-12], p.R437Q [1, 13], p.R437W [1], p.R437G [14], p.M436T, p.L253P [9], p.I157T, p.T472M [15], p.F160C [1], p.T62I [1], p.R351P, p.H278R [16], p.R721S [17], p.T820M [17], and spectrin protein. b Evolutionary conservation of the mutation p.I162M. c Evolutionary conservation of the mutation p.R883L

p.T27I [18]), two three-nucleotide in-frame deletion (c.2608_2610delGAG; p.E870del [19] and c.1276_1278delCTG; p.L426del), and two larger in-frame deletion (c.1886_1900del15; p.L629_R634del [8] and c.1592_1630del39; p.E532_M544del [5]). The variant (p.R480W) was found in three unrelated families. The patients suffered from ataxias with early-onset age and showed global developmental delay. Ellen et al. identified a p.T472M substitution in a late-onset SCA5 family. The proband of the family developed progressive gait ataxia in her early 50s [15]. A heterozygous three-nucleotide inframe deletion mutation (c.2608_2610delGAG; p.E870del) was detected in the first Japanese family [19]. Five patients in the family presented limb ataxia and dysarthria with late-onset age. Three different variants on the arginine at 437 of spectrin protein including p.R437G, p.R437Q, and p.R437W were reported in four pedigrees. The probands all displayed ataxia, dysarthria, and developmental delay with early-onset age. The phenotypes of probands in previous SCA5 families are shown in Table 2.

SCA5 is rare autosomal-dominant ataxias, especially in Chinese people. Only one of the above variants was reported in a 19-year-old Chinese girl presenting with progressive unsteady gait while running from the age of 11 years. Here, we identified two novel variants of SPTBN2 responsible for SCA5 in a Chinese family and a 64-year-old male with onset 


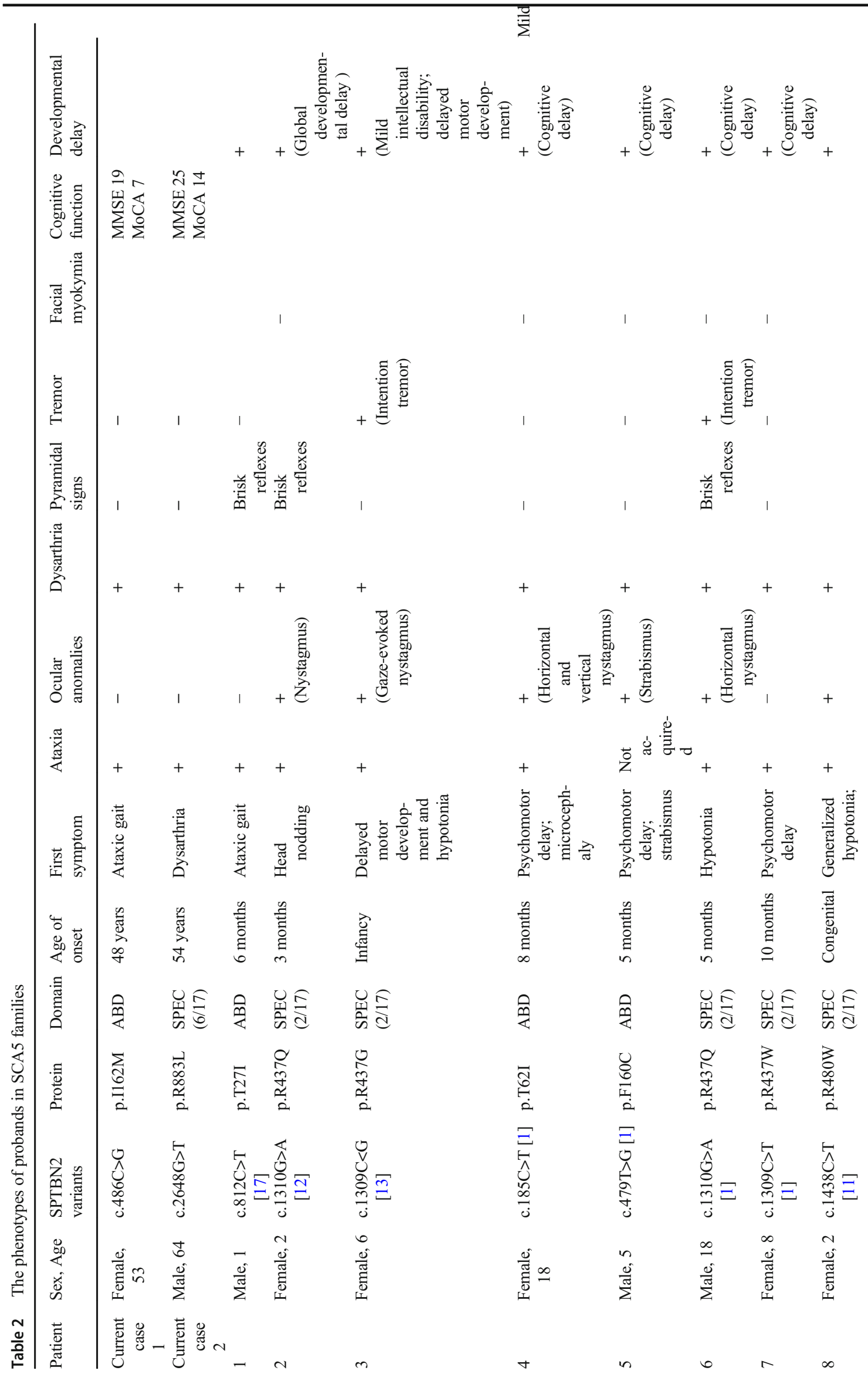




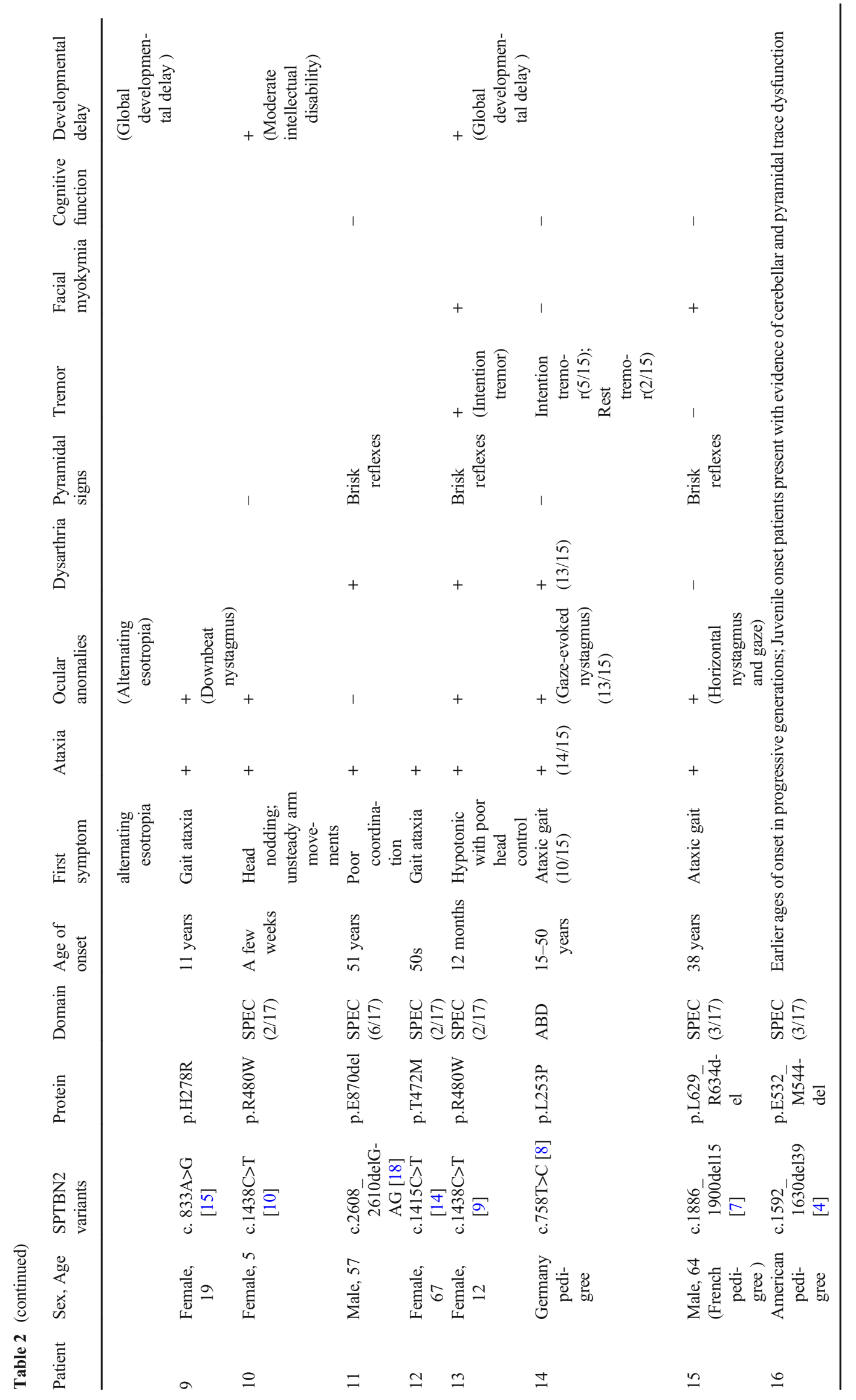

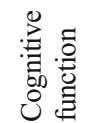

丞旁

ᄒัّ

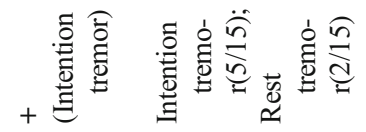

胥

离

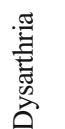

产

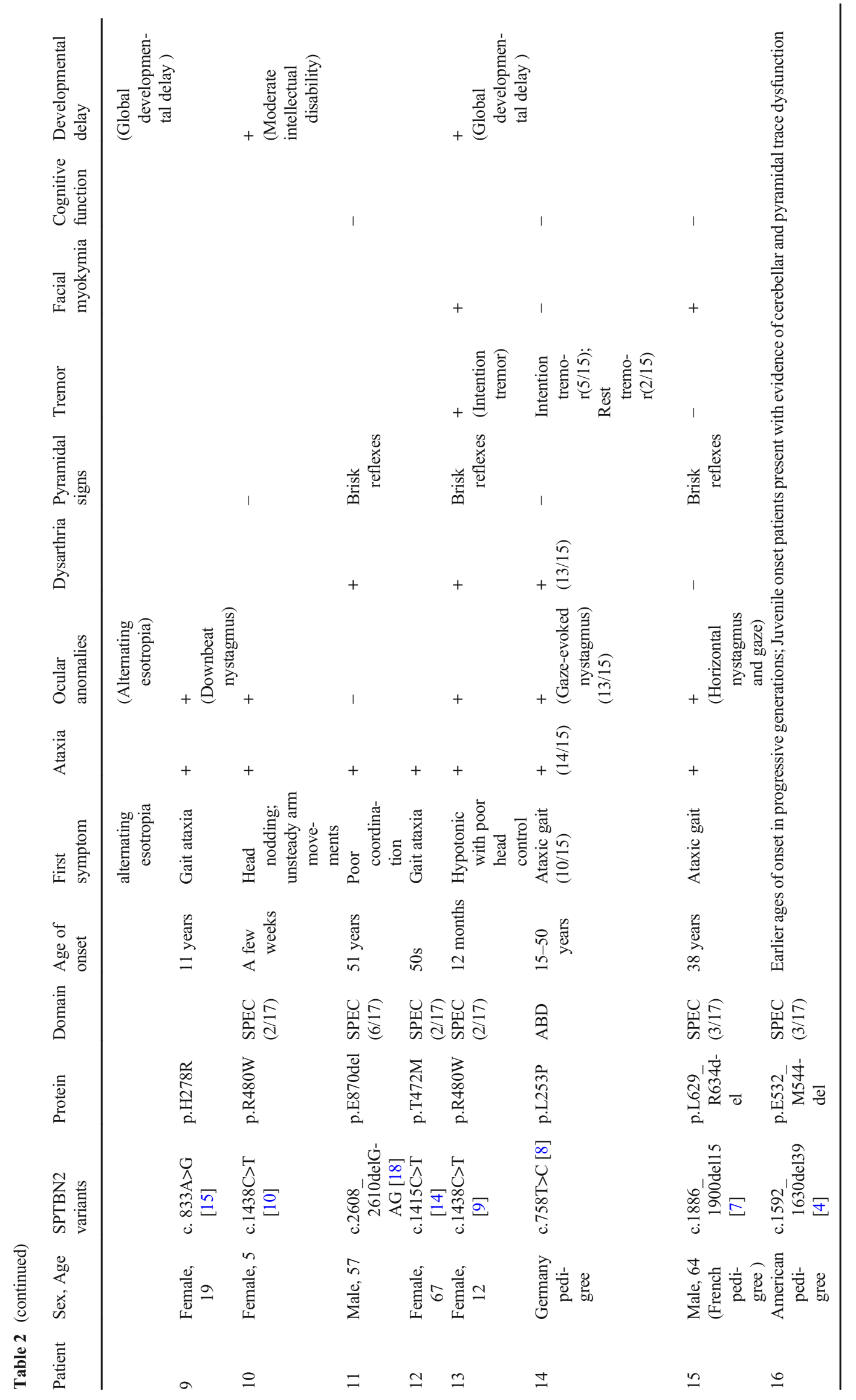

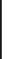

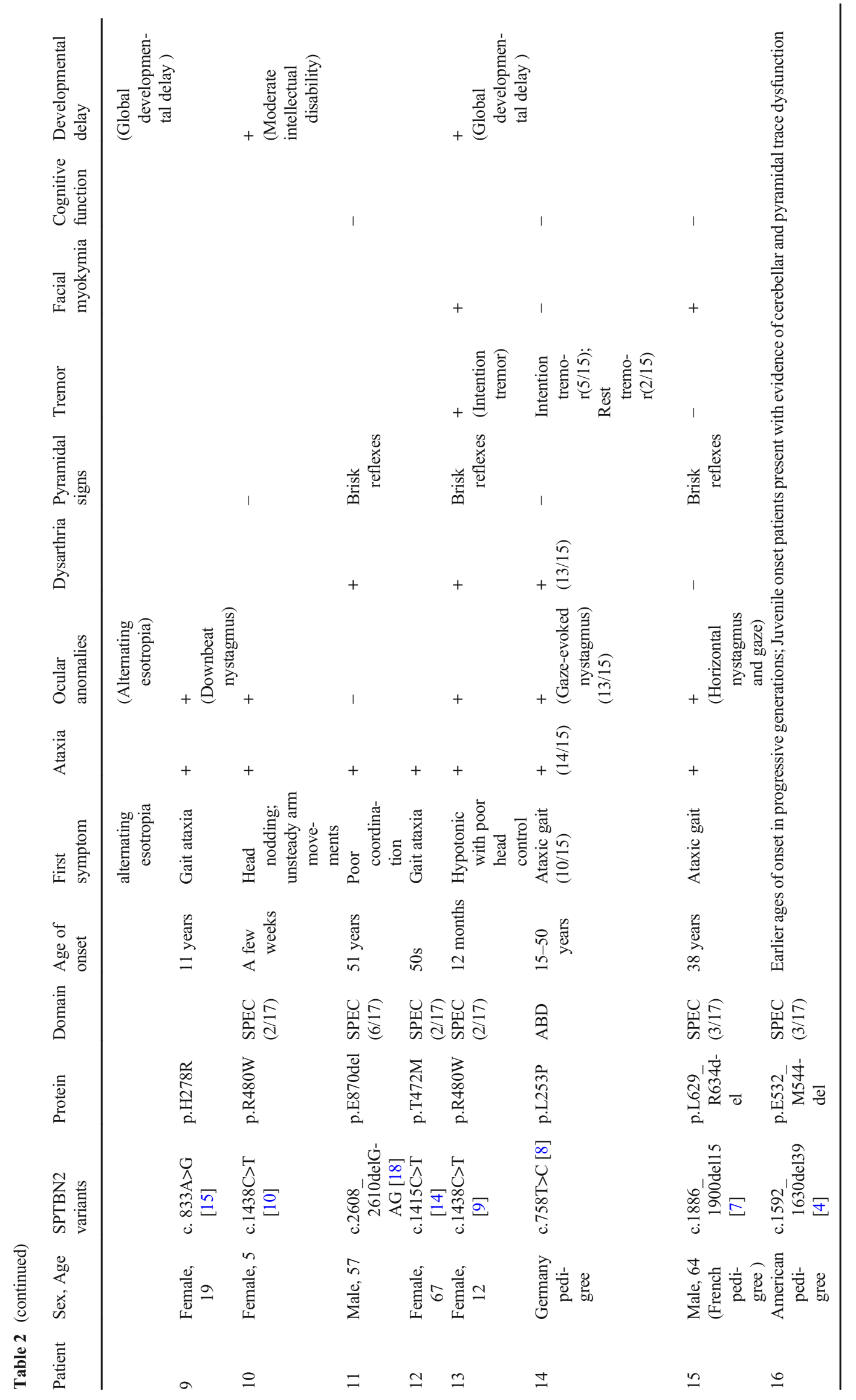

壳 产

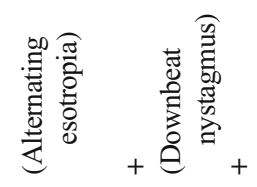

$+\quad+\quad+\stackrel{\frac{n}{n}}{\frac{n}{2}}$

嗬

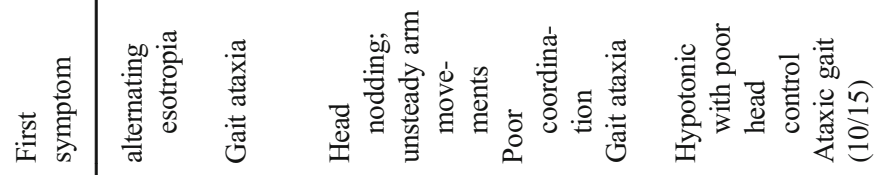

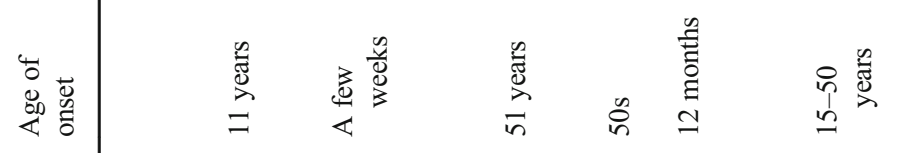

ีํำ

空空

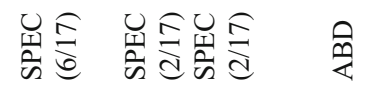

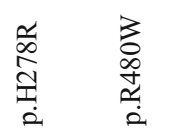

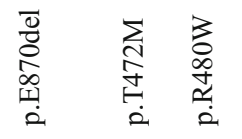

气ิ

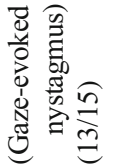

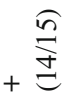

:

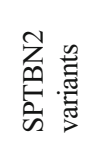

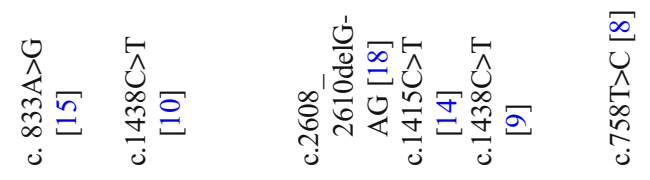

兽

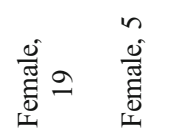

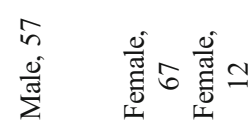

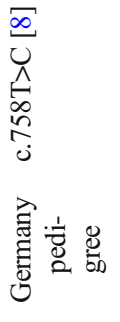

$=\simeq \Omega$

$\pm$

离

유ํ 
at the fifth decade. It may help to develop genetic counseling and investigate targeted pharmaceutical interventions.

SPTBN2 encodes $\beta$-III spectrin protein, including $\mathrm{CH}$ domains (the actin/ARP1 binding site), 17 spectrin repeats involved in the formation of the heterotetrameric $\alpha-\beta$ spectrin complex, and PH domains (phosphatidylinositol lipids binding site) [20]. $\beta$-III spectrin was primarily expressed in Purkinje cell bodies, dendrites, and axons of the cerebellum. Loss of $\beta$-spectrin resulted in marked Purkinje cell loss, dendritic atrophy, and significant thinning of the molecular layer in SCA5 [5]. The mechanism may be decreased sodium currents and deficits in glutamatergic neurotransmission [21-23]. The first variant (c.486C $>$ G p.I162M) in our study was located at $\mathrm{CH}$ domain affecting a highly conserved residue. Interestingly, a 5 -year-old child with early-onset psychomotor delay and strabismus carrying a different de novo variant but affecting the nearby amino acid (c.479T>C, p.F160C) has been recently reported [1]. Structural analysis revealed that it caused the loss of the hydrophobic interactions with Trp66 and Leu98, modifying the interface of the CH-1 domain with actin. It was predicted that p.I162M may also have a role in regulating the $\mathrm{CH}-1$ domain binding with actin. The second variant in our study (c.2648G $>\mathrm{T}$ p.R883L) was located in the 6th spectrin repeats domain which participated in the formation of the heterotetrameric $\alpha$ - $\beta$-spectrin complex. The two variants were predicted probably damaging and disease-causing by structure analysis. Functional studies should be urgently needed.

\section{Conclusion}

In this study, we identified two novel heterozygous variants of SPTBN2 resulting in severe ataxia which further delineated the correlation between the genotype and phenotype of SCA5, and pathogenesis of variants in SPTBN2 should be further researched.

Acknowledgements We would like to thank all participants for their willingness to join this study.

Author contribution All authors contributed to the study conception and design. Material preparation, data collection, and analysis were performed by Xianli Bian and Shang Wang. The first draft of the manuscript was written by Xianli Bian, and all authors commented on previous versions of the manuscript. All authors read and approved the final manuscript.

Funding The present study was supported by the Seed Fund of the 2nd Hospital of Shandong University (grant number S2015010002) and the Natural Science Foundation of Shandong Province (grant number ZR2020QH097).
Data Availability The data that support the findings of this study are available from the corresponding author upon reasonable request.

Code availability Not applicable.

\section{Declarations}

Ethics approval This study was performed in line with the principles of the Declaration of Helsinki. And the study was approved by the ethics committees of the Second Hospital of Shandong University (Jinan).

Consent to participate Written informed consent was obtained from all the participants.

Consent to publish Not applicable.

Conflict of interest The authors declare no competing interests.

Open Access This article is licensed under a Creative Commons Attribution 4.0 International License, which permits use, sharing, adaptation, distribution and reproduction in any medium or format, as long as you give appropriate credit to the original author(s) and the source, provide a link to the Creative Commons licence, and indicate if changes were made. The images or other third party material in this article are included in the article's Creative Commons licence, unless indicated otherwise in a credit line to the material. If material is not included in the article's Creative Commons licence and your intended use is not permitted by statutory regulation or exceeds the permitted use, you will need to obtain permission directly from the copyright holder. To view a copy of this licence, visit http://creativecommons.org/licenses/by/4.0/.

\section{References}

1. Nicita F, Nardella M, Bellacchio E, Alfieri P, Terrone G, Piccini G, Graziola F, Pignata C, Capuano A, Bertini E, Zanni G (2019) Heterozygous missense variants of SPTBN2 are a frequent cause of congenital cerebellar ataxia. Clin Genet 96:169-175

2. Rosini F, Pretegiani E, Battisti C, Dotti MT, Federico A, Rufa A (2020) Eye movement changes in autosomal dominant spinocerebellar ataxias. Neurol Sci 41:1719-1734

3. Ranum LP, Schut LJ, Lundgren JK, Orr HT, Livingston DM (1994) Spinocerebellar ataxia type 5 in a family descended from the grandparents of President Lincoln maps to chromosome 11. Nat Genet 8: 280-284

4. Dick KA, Ikeda Y, Day JW, Ranum LP (2012) Spinocerebellar ataxia type 5. Handb Clin Neurol 103:451-459

5. Ikeda Y, Dick KA, Weatherspoon MR, Gincel D, Armbrust KR, Dalton JC, Stevanin G, Durr A, Zuhlke C, Burk K, Clark HB, Brice A, Rothstein JD, Schut LJ, Day JW, Ranum LP (2006) Spectrin mutations cause spinocerebellar ataxia type 5. Nat Genet 38:184 190

6. Klockgether T, Mariotti C, Paulson HL (2019) Spinocerebellar ataxia. Nat Rev Dis Primers 5:24

7. Richards S, Aziz N, Bale S, Bick D, Das S, Gastier-Foster J, Grody WW, Hegde M, Lyon E, Spector E, Voelkerding K, Rehm HL (2015) Standards and guidelines for the interpretation of sequence variants: a joint consensus recommendation of the American College of Medical Genetics and Genomics and the Association for Molecular Pathology. Genet Med 17:405-424

8. Stevanin G, Herman A, Brice A, Durr A (1999) Clinical and MRI findings in spinocerebellar ataxia type 5. Neurology 53:1355-1357 
9. Burk K, Zuhlke C, Konig IR, Ziegler A, Schwinger E, Globas C, Dichgans J, Hellenbroich Y (2004) Spinocerebellar ataxia type 5: clinical and molecular genetic features of a German kindred. Neurology 62:327-329

10. Jacob FD, Ho ES, Martinez-Ojeda M, Darras BT, Khwaja OS (2013) Case of infantile onset spinocerebellar ataxia type 5. J Child Neurol 28:1292-1295

11. Parolin Schnekenberg R, Perkins EM, Miller JW, Davies WI, D'Adamo MC, Pessia M, Fawcett KA, Sims D, Gillard E, Hudspith K, Skehel P, Williams J, O'Regan M, Jayawant S, Jefferson R, Hughes S, Lustenberger A, Ragoussis J, Jackson M, Tucker SJ, Nemeth AH (2015) De novo point mutations in patients diagnosed with ataxic cerebral palsy. Brain J Neurol 138:18171832

12. Nuovo S, Micalizzi A, D'Arrigo S, Ginevrino M, Biagini T, Mazza T, Valente EM (2018) Between SCA5 and SCAR14: delineation of the SPTBN2 p.R480W-associated phenotype. Eur J Hum Genet 26: 928-929

13. Accogli A, St-Onge J, Addour-Boudrahem N, Lafond-Lapalme J, Laporte AD, Rouleau GA, Riviere JB, Srour M (2020) Heterozygous missense pathogenic variants within the second spectrin repeat of SPTBN2 lead to infantile-onset cerebellar ataxia. J Child Neurol 35:106-110

14. Mizuno T, Kashimada A, Nomura T, Moriyama K, Yokoyama H, Hasegawa S, Takagi M, Mizutani S (2019) Infantile-onset spinocerebellar ataxia type 5 associated with a novel SPTBN2 mutation: a case report. Brain Dev 41:630-633

15. Cho E, Fogel BL (2013) A family with spinocerebellar ataxia type 5 found to have a novel missense mutation within a SPTBN2 spectrin repeat. Cerebellum 12:162-164

16. Liu LZ, Ren M, Li M, Ren YT, Sun B, Sun XS, Chen SY, Li SY, Huang XS (2016) A novel missense mutation in the spectrin beta nonerythrocytic 2 gene likely associated with spinocerebellar ataxia type 5. Chin Med J 129:2516-2517
17. Fogel BL, Lee H, Deignan JL, Strom SP, Kantarci S, Wang X, Quintero-Rivera F, Vilain E, Grody WW, Perlman S, Geschwind DH, Nelson SF (2014) Exome sequencing in the clinical diagnosis of sporadic or familial cerebellar ataxia. JAMA Neurol 71:12371246

18. Rea G, Tirupathi S, Williams J, Clouston P, Morrison PJ (2020) Infantile onset of spinocerebellar ataxia type 5 (SCA-5) in a 6 month old with ataxic cerebral palsy. Cerebellum 19:161-163

19. Wang Y, Koh K, Miwa M, Yamashiro N, Shindo K, Takiyama Y (2014) A Japanese SCA5 family with a novel three-nucleotide inframe deletion mutation in the SPTBN2 gene: a clinical and genetic study. J Hum Genet 59:569-573

20. Clarkson YL, Gillespie T, Perkins EM, Lyndon AR, Jackson M (2010) Beta-III spectrin mutation L253P associated with spinocerebellar ataxia type 5 interferes with binding to Arp1 and protein trafficking from the Golgi. Hum Mol Genet 19:3634-3641

21. Clarkson YL, Perkins EM, Cairncross CJ, Lyndon AR, Skehel PA, Jackson M (2014) beta-III spectrin underpins ankyrin R function in Purkinje cell dendritic trees: protein complex critical for sodium channel activity is impaired by SCA5-associated mutations. Hum Mol Genet 23:3875-3882

22. Perkins EM, Suminaite D, Clarkson YL, Lee SK, Lyndon AR, Rothstein JD, Wyllie DJ, Tanaka K, Jackson M (2016) Posterior cerebellar Purkinje cells in an SCA5/SPARCA1 mouse model are especially vulnerable to the synergistic effect of loss of beta-III spectrin and GLAST. Hum Mol Genet 25:4448-4461

23. Efimova N, Korobova F, Stankewich MC, Moberly AH, Stolz DB, Wang J, Kashina A, Ma M, Svitkina T (2017) betalII spectrin is necessary for formation of the constricted neck of dendritic spines and regulation of synaptic activity in neurons. J Neurosci Off J Soc Neurosci 37:6442-6459

Publisher's Note Springer Nature remains neutral with regard to jurisdictional claims in published maps and institutional affiliations. 